\title{
Establishment of a national sports training camp in Koya
}

\author{
J. A. Karadaghy \\ School of Physical Education, Faculty of Education, Koya University, \\ Kurdistan, Iraq
}

\begin{abstract}
The idea of establishing a national sports training camp in the city of Koya is an attempt to find a way to invest resources, human and material capabilities available there, for instance the stadium and the sports hall in the Faculty of Physical Education and Koya Youth Centre as well as the tourist resorts in the Haibat-Sultan (Kosar) and Koya Palace Hotel. All of this has a positive impact on the level of sports teams, especially sports that use those capabilities. In turn, Koya city will have an effective support on the sports movement in Iraq in general and Kurdistan in particular. In fact, the proposed method of establishing the sports training camp is different from what has been used by athletes in terms of using local facilities and geographic location.
\end{abstract}

\section{Introduction}

The idea of setting training camps rises when the sport teams and national teams of Iraq going to train in the Arab and European countries in order to prepare those teams to participate in the regional matches, continental tournaments and global championships. Training camps helps the sport teams to increase expertise through intensive programs where for being one of the main factors for the development of the sports movement and this means that Iraq in dire need of permanent camps to train athletes.

It can be noted that there is some negligence in the construction plans and the advancement in Koya city compared to rapid development that has occurred in recent years to some cities in Kurdistan. From this sense, it is a common belief that the need to put forward ideas and proposals may lead to the possibly the application of those ideas into practical reality. As this idea meets the topics of 
the (First international Symposium on urban development "Koya as a case study"), proposing the idea of establishing a national sports training camp in Koya city, wishing that the responsible personals study this idea in collaboration and consultation with the relevant authorities in Kurdistan, which requires allocation of adequate budget for the completion of this camp, which will benefit large sport movement as a whole Iraqi sports as it provides an opportunity for the city of Koya to take his share and to take advantage of privileges for the purpose of tourism in Kurdistan where the geographical nature and climate which are also ideal for the establishment of such camps.

This idea came after building swimming pool, playgrounds and sports hall in the new building of the School of Physical Education, at Koya University, also the existence of Koya Youth Centre and Koya Palace Hotel with the University guesthouse inside its campus as well as having the Kosar group of the multi tourism facilities that includes restaurants and motels besides the Chnarok resorts. All of the above factors contribute on wide range to the process of human and sport investment, which has economical outcomes, supports the development and investment process in Kurdistan. The Investment Promotion Law in the Kurdistan Region number (89) for the year 2004 came in order to create a climate attractive to the investment process and remove legal obstacles in front of it, also making the way for the recruitment of national capital and foreign investment are contributing to the economic development process to compensate for the losses suffered by Kurdistan by the destruction of infrastructure, because more than $97 \%$ of the cities and villages of Kurdistan have been destroyed during (1985-1990) including Koya [1] Figures 1 and 2 show clear locations of the university and a snapshot of Kosar resort respectively.

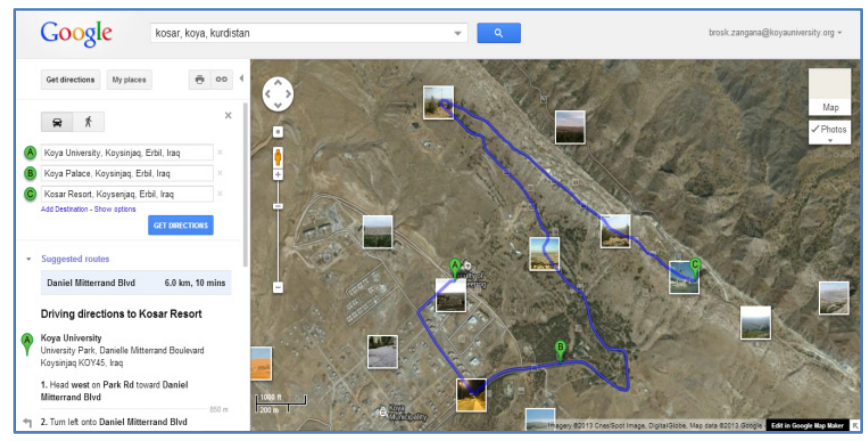

Figure 1: $\quad$ A map demonstrates the location of Koya University, Koya Palace Hotel and Kosar resort by Google maps.

Hence, it is refer to the importance of benefiting from the experiences of the developed countries in the field of sport investment where nowadays there is a global trend of privatization that multiple forms in different institutions as a tool of economic reform, which aims to shift from the public sector to the private 


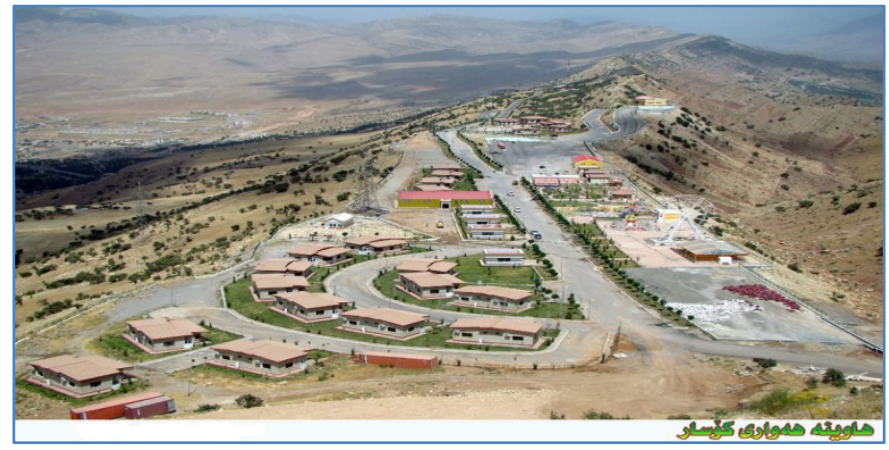

Figure 2: $\quad$ Snapshot of Kosar resort.

sector as stated in the study by Sayed Abdul Jawad Al Sayed [2] about the potentials of the Faculty of Physical Education in Port Said in the field of sports marketing services.

The study showed the methods of sports marketing services through the potential of the Faculty of Physical Education in Port Said and reached to the possibility of providing marketing services for all sports teams and local bodies, Arab and international as follows:

- Construction and stadiums.

- $\quad$ Multi-purpose sports halls.

- $\quad$ The place for sport therapeutics.

- $\quad$ Provide technical laboratories for testing and measurement in the fields of (physiological, morphological, psychological, Movement Sciences and steroids [2, 3].

\section{The training camp: definition}

The training camp is a building or facility, which will be held in which the type of physical activity required in preparation for participation in sports tournaments at the local and international levels and includes the stadium for football and swimming pool and the hall's internal games handball, basketball, volleyball, tennis and other games and field sprinting and accessories. In addition to the rooms, massage and sauna baths and ambulance station and stores should be included. On the other hand, it also requires a hotel, where the athletes can sleep and this should include all amenities as well as a hall for lectures and view movies and the buildings attached to the administration in accordance with the training camp. 


\section{A brief overview of the experiences of training camps in the United States and Britain [4, 5]}

Jay et al. [4] explained the steps that are necessary to be followed by the administration and specialists responsible for these clubs to attract sponsors. He showed that the clubs administrations offer in terms of features and facilities for individuals and working to increase them as well as developing work programs that must be followed.

Adams [5] in her study showed the importance of the sports care in Britain, which is estimated at billion pounds. The presents the factors attracting the corporate sponsors and guarantors of local and international sport and give those sponsoring companies the right to contact decision-makers at the official level or local.

\section{The steps of preparing a sports training camp in Koya}

First: Forming a work team composed of several specialties experienced in the field of sports management and who contribute to the establishment of the camp to taking fundamentalist approvals and estimate the funds required and make sure to match the required specifications camp.

Second: After selecting the team, who is planning to set up the camp, it must identify the target of the camp and what is required by setting such camps.

Third: Determine the quality of the beneficiaries and users of the training camp.

Fourth: Determine the types of sport games according to available resources and expanding them to suit future development of the camp.

Fifth: Provide special technicians for the permanent maintenance and to continue the efficiency of the camp.

For more demonstration see the photos below of a standard sports training camp in figure 3, Olympic swimming pool in figure 4 and Hall of Indoor Winter Sports Games as in figure 5.

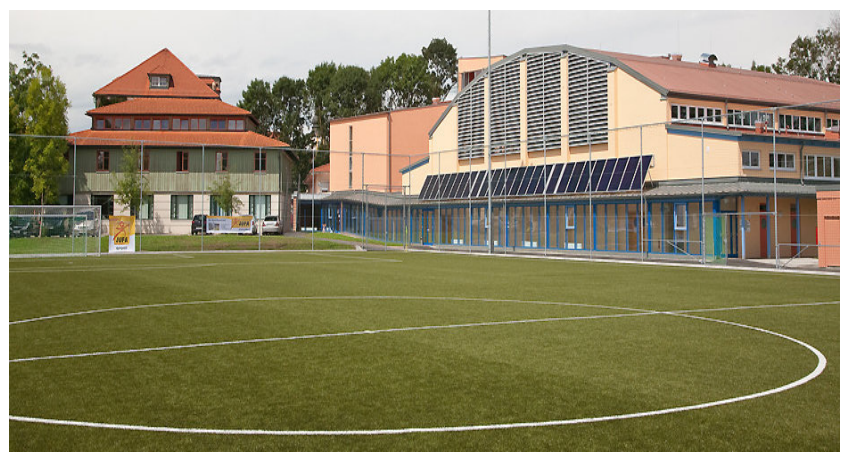

Figure 3: $\quad$ Standard sports training camp. 


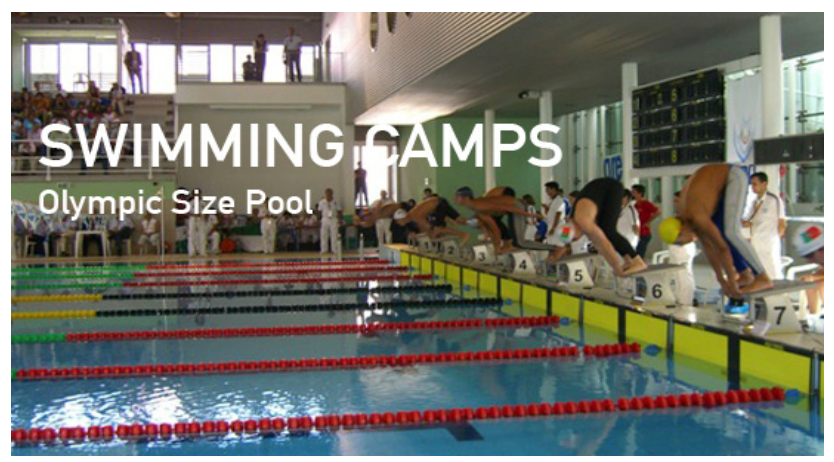

Figure 4: $\quad$ Standard Olympic swimming pool.

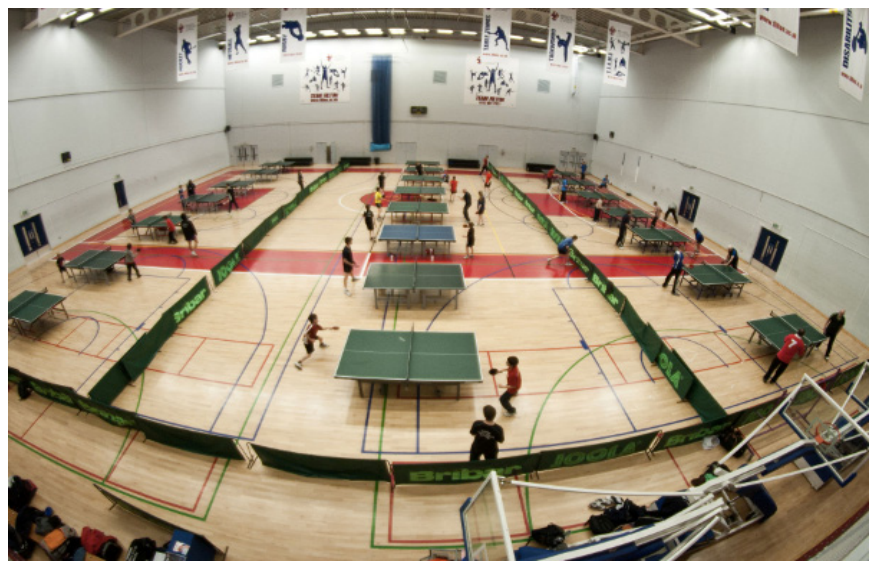

Figure 5: $\quad$ Hall of Indoor Winter Sports Games.

\section{The importance of establishing a national sports training camp in Koya}

As a matter of fairness, it can be said that Iraqi Kurdistan was able to achieve a qualitative leap in the field of sports in spite of all the challenges and obstacles experienced especially in the past few years. It is obvious that Kurdistan needs at the moment to draft a sports marketing project as a result of appropriate security conditions experienced by the Kurdish people. This project requires a sports institution, physical potentials and human resources. The importance of the project lies in the following:

1 - It is the first of its kind in Iraq, and the idea of the camp is unique and a leader in the sports field and can be initially difficult, but to achieve the idea associated with the provision of financial resources and human 
resources supported by the Olympic Committee and the Ministry of Culture and coordination with city council and the municipality as well as Koya University.

2 - It considers a real indication to reduce the financial cost to the preparation and rehabilitation of Iraqi sports teams that assess camps in the Arab or European countries, because the exchange will be by Iraqi currency and not by foreign currency.

3 - Abound need to this camp for the few existence or not having a safe environment in central and southern Iraq that have the perfect character for the establishment of training camps.

4 - The funding process is a tool of planning to achieve the goals of universities and funding is one of the main problems faced by officials in the administration of scientific institutions, because the government support does not meet their needs and aspirations. Hence, highlights the importance of investing sports as a running and increasing the capital and the resources by running sports and the exploitation of the potentials available to attract the attention of sports fans.

5 - To benefit from the expertise and plans for sports teams and their coaches and efficient transfer of experiences to Kurdistan athletes.

6 - Increase public turnout on sports teams in the training camp and the opening channels with media to express their views and their desires to attract and polarize the young people and applicants in sports circles.

Finally, the idea of the establishment of this camp in the city of Koya is mine pursuant voluntarily without thinking about the achievement of certain personal profits and God is my witness.

\section{References}

[1] An economic report publication, the Iraqi Al-Sabah, No. 749, January 21, 2006 (originally in Arabic).

[2] Sayed Abdul Jawad Al Sayed (1999): "About the potentials of Physical Education in Port Said in the field of sports marketing services," the First National Conference for University Marketing Services, Experiences and Judgments, Faculty of Commerce, Cairo University (originally in Arabic).

[3] Aleya Abdel Moneim Hassan Hijazi and Ahmed El-Shafei, Sports marketing strategy and investment in various sports institutions, Al Wafaa printing house, Alexandria, 2009, p 16 (originally in Arabic).

[4] Arnold Jay et al., (1995): "Clubs sports in Colleges and Universities National Association for Sport and Physical Education”, Washington DC.

[5] Jane Adams: Sport Sponsorship in Britain, the Institute of Sports Sponsorship, November 1997. 